\title{
Comparison of Static Aerodynamic Data Obtained in Dynamic Wind Tunnel Tests and Numerical Simulation Research
}

\author{
Habib BELAIDOUNI, Marija Đ. SAMARDŽIĆ, Damir D. JERKOVIĆ, Saša ŽIVKOVIĆ, Zoran RAJIĆ, Dušan ĆURČIĆ, \\ Aleksandar KARI
}

\begin{abstract}
The aerodynamic data obtained in the static and dynamic wind tunnel tests are presented in this paper. The tests are performed in the T-38 wind tunnel facility of the Military Technical Institute in Belgrade. Normal force and pitching moment in static and dynamic tests are measured using semiconductor five-component strain gauge balance. This specific five-component balance is dynamic derivative balance. Forced oscillation technique is used for the dynamic measurements applied in the T38 wind tunnel. The wind tunnel data are compared with aerodynamic data determined using flow simulations with RANS (CFD) code and applied models of turbulence. The aerodynamic data calculated using semi-empirical prediction were the initial values for the numerical research. The experimental and numerical data are presented for the one standard missile model (Modified Basic Finner Model) for three flow regime Mach numbers.
\end{abstract}

Keywords: aerodynamic coefficients; internal balance; RANS CFD; semiconductor strain gauge; turbulent viscosity; wind tunnel

\section{$1 \quad$ INTRODUCTION}

A wind tunnel strain gauge balance measures aerodynamic load and supports a model in a wind tunnel test section. The main function of the wind tunnel balance is to resolve the total aerodynamic load on a model into a number of components. Wind tunnel balances are classified into one-component and multi component balances according to the number of aerodynamic load components measured by the balance. Types of wind tunnel balances are varied, so each of them is appropriate to the particular set of circumstances [1]. The balances can also be classified by the location at which they are placed. If a balance is located outside of a model or a wind tunnel test section, the balance is referred as an external balance [2, 3] and if it is located inside a model, it is referred as an internal balance [4].

A strain gauge balances are the most widely used for forces and moments measurements in wind tunnels. Along with the five-component and six-component stingtype strain gauge balances, there are a number of special strain gauge balances to meet the requirements of special measurements, for example, hinge moment balances, dynamic derivative balances, jet balance, Magnus balances, rotating balances, rotating wing balances, minirolling moment balances, micro-range balances, and so on [5].

The strain gauge balance is designed in such a way that strains in its particular sections of the structure are mostly proportional to one aerodynamic component acting on the model. By bonding resistance strain gauges to these appropriate sections of the structure and connecting them to the form of Wheatstone bridges, electrical outputs proportional to the various forces and moments can be obtained [6]. Two most common types of strain gauges are metal foil-type strain gauge and semiconductor-type strain gauge [7]. The foil strain gauges are commonly used in wind tunnel experiments. The use of semiconductor strain gauges is not widely applied in experimental measurements. In almost all cases, measuring bridges on the strain gauge balances for static aerodynamic tests are formed from foil-type strain gauges. The adverse temperature dependent effects are more severe with semiconductor strain gauges than with foil-type gauges and these effects are more difficult to compensate. On the other hand, for normally available semiconductor strain gauges the ratio between the measured strain and output signal given by the strain gauge is about fifty to sixty times that the foil-type strain gauge [8]. The large signal given by semiconductor strain gauges is particular advantage in the presence of strong interference fields. The high sensitivity is the main reason for using semiconductor strain gauges for the measurements of very small loads.

The five-component dynamic derivative balance presented in this paper is designed for tests in the T-38 wind tunnel in the Military Technical Institute in Belgrade (VTI) [9]. One of the main aspects of the presented research was to check the measurement accuracy of static aerodynamic data obtained using the semiconductor strain gauge balance, which is primarily intended for dynamic wind tunnel tests. In dynamic wind tunnel tests, whose main task is determination of the dynamic aerodynamic data, static aerodynamic data are obtained too. These are reasons why the accuracy of measurement of the static aerodynamic data with the dynamic balance is of great interest.

The T-38 wind tunnel data are compared with the results of semi-empirical methods and the results of the numerical simulation researches. The semi-empirical results of aerodynamic data are developed according to two different methods [10-12] and represented as the semi-empirical aerodynamic prediction results. The numerical results of aerodynamic data are derived from the numerical simulations, using the different resolutions of the numerical domain and the different turbulent viscosity models. Those results are represented as numerical aerodynamic prediction results $[13,14]$.

\section{EXPERIMENTAL TEST AND PROCEDURE}

The T-38 wind tunnel of the VTI, Fig. 1, is a blowdown-type pressurized wind tunnel with $1.5 \times 1.5 \mathrm{~m}^{2}$ 
square test section. Mach number in the range of $0.2-4.0$ can be achieved in the test section.

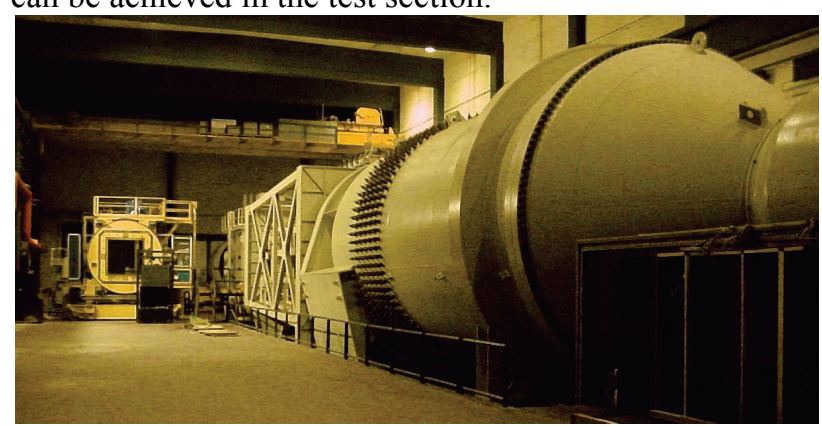

Figure 1The T-38 wind tunnel

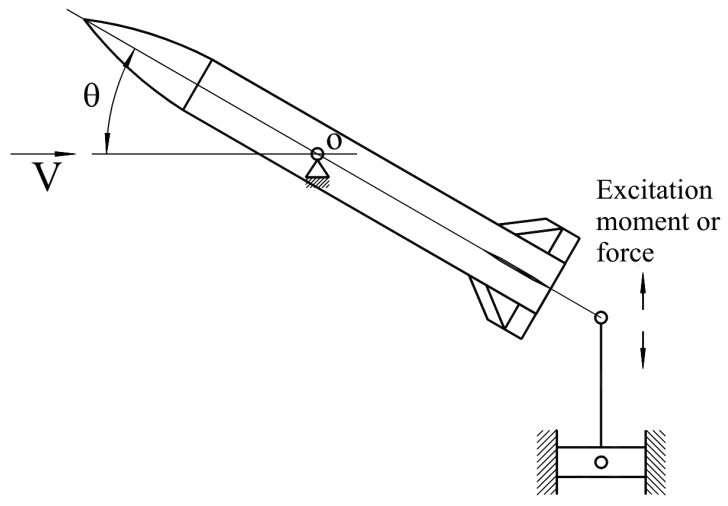

Figure $2 \mathrm{~A}$ model oscillation scheme in pitch plane

The forced oscillation technique is used for the dynamic wind tunnel tests [15]. A wind tunnel model is forced to oscillate in the single degree of freedom (primary degree of freedom) with constant frequency and small amplitude. During the experiment, aerodynamic reactions in the primary and secondary degrees of freedom are measured. Those reactions in turn yield relevant static stability derivatives, dynamic direct stability derivatives, cross and cross-coupling stability derivatives.

The basic scheme of the model oscillation in pitch plane is given in Fig. 2, where $V$ is free stream velocity and $\theta$ is angular oscillatory motion in pitch. This paper presents results obtained using the $\mathrm{T}-38$ pitch/yaw apparatus.

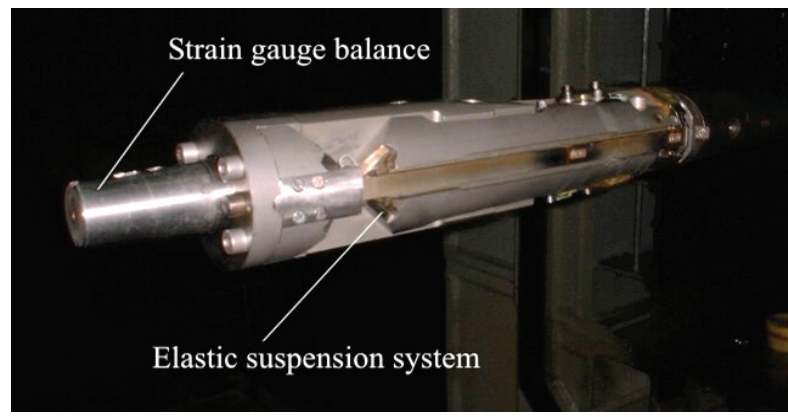

Figure 3 Pitch/yaw apparatus

The T-38 pitch/yaw apparatus is full-model forced oscillation apparatus with the primary angular oscillation around a transversal axis (pitch or yaw) of the model and with capability of measuring the aerodynamic reaction in the primary degree of freedom as well as in secondary degrees of freedom. The wind tunnel model is attached to the front cone of the internal five-component strain gauge balance, Fig. 3. The sensor for the detection of the model primary oscillatory motion is located on the elastic suspension system of the apparatus.

Amplitudes of the excitation moment are measured by pitching moment measuring bridge on the internal dynamic derivative balance.

The static and dynamic stability derivatives in dynamic tests are obtained from:

- amplitude of the model primary oscillatory motion,

- amplitude of excitation moment,

- frequency of the model primary oscillatory motion,

- $\quad$ phase shift between the excitation moment and model primary oscillatory motion.

\subsection{The Five-Component Dynamic Derivative Balance}

The design and manufacturing of wind tunnel balances are based on the very contrasting requirements. A model and wind tunnel balance in a wind tunnel test section is shown in Fig. 4.

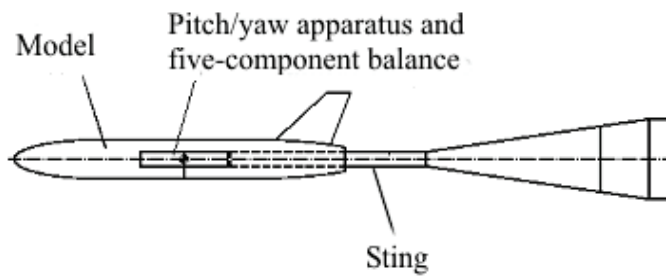

Figure 4 Model and wind tunnel balance in a wind tunnel tests section

In a design of a strain gauge balance a large number of requirements have be considered such as the type of wind tunnel, the range of Mach number, the maximum allowable geometric dimensions of the balance, the form and dimensions of the connection between the balance and model as well as those between the balance and a sting, the number of aerodynamic components and corresponding design loads, the model mass and the positions of the centre of mass, the location of the moment reference centre. In the blowdown-type wind tunnels, as T-38 wind tunnel is, balances have to be designed for huge loads at start and the end of the wind tunnel runs. Large transient loads during starting and stopping wind tunnels runs on high Mach numbers is common characteristics of blowdown wind tunnels. The intensity of the transient loads is proportional to the model size and wind tunnel stagnation pressurized. Researchers and constructors in the blowdown-type wind tunnels have opted for design and manufacturing of the model, sting, internal wind tunnel balances and measurement equipment from steel alloys of high quality. Much attention is also paid to increasing the stiffness of wind tunnel balances and stings [16].

The five-component dynamic derivative balance, for the T-38 pitch/yaw apparatus, has to enable measurement in supersonic requiem of flow where presence of the transient loads requires stiff balance. An important requirement in any forced-oscillation apparatus and wind tunnel balance for damping derivative measurements is its structural rigidity. This is especially important requirement in measurements of the aerodynamic reactions in the secondary degrees of freedom. Small amounts of structural distortion under the action of the 
oscillatory aerodynamic loading can give rise to considerable error in the measurement of the aerodynamic and structural reactions from the secondary degrees of freedom. On the other hand, since the signals from the balance measuring bridges are primarily proportional to the strain in the balance measuring sections, very important requirement in the strain gauge balance design is optimal signal level from the measuring bridges. The dynamic derivative balance has to ensure accurate measurement of the very low values of the aerodynamic reactions produced by the model oscillatory motion.

The five-component balance with foil-type strain gauges, which was previously used in the T-38 wind tunnel dynamic derivative measurements, is shown in Fig. 5. Tab. 1 lists the design loads of the balance, maximum values of the output signals and gives a summary of achieved accuracy in the balance calibration, where FS is full scale of the balance component, $Y$ is aerodynamic side force, $Z$ is aerodynamic normal force, $L$ is aerodynamic rolling moment, $M$ is aerodynamic pitching moment and $N$ is aerodynamic yawing moment.

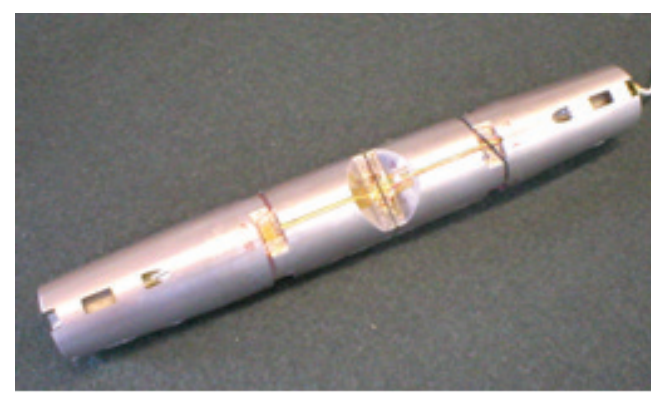

Figure 5 Five-component wind tunnel balance with foil strain gauges

The series of the T-38 wind tunnel dynamic measurements, using the balance with foil-type strain gauges, have shown that in some signals in the model primary degree of freedom and in the majority of the signals in the secondary degrees of freedom the frequency of the primary oscillation cannot be detected. This balance has very law accuracy of the determining oscillatory components of the signals. It is known that foil strain gauges provide required accuracy of the measurements in static wind tunnel tests.

Table 1 Design loads of the five-component foil strain gauge balance

\begin{tabular}{|c|c|c|c|}
\hline Component & $\begin{array}{c}\text { Design load } \\
\text { (N/Nm) }\end{array}$ & $\begin{array}{c}\text { Maximum value } \\
\text { of the output } \\
\text { signals (mV) }\end{array}$ & $\begin{array}{c}\text { Maximum } \\
\text { errors } \\
(\% \text { FS })\end{array}$ \\
\hline$Y$ & 7000 & 4.5 & 0.12 \\
\hline$Z$ & 10100 & 6.2 & 0.19 \\
\hline$L$ & 300 & 4.1 & 0.17 \\
\hline$M$ & 660 & 9.8 & 0.25 \\
\hline$N$ & 350 & 5.2 & 0.15 \\
\hline
\end{tabular}

Knowledge that semiconductor strain gauges enable determination of the oscillatory components of the signals even if they are deeply hidden in the noise, led to their application in the T-38 wind tunnel dynamic measurements [17]. The dynamic derivative balance with semiconductor strain gauges is shown in Fig. 6. The balance diameter is $40 \mathrm{~mm}$. This dynamic balance is manufactured out of one piece shaping a particular section to obtained three measuring sections.
The forward and backward measuring sections are used for the measurement of the normal force and pitching moment, as well as the side force and yawing moment. These two measuring sections are shaped as a three-bare cage. The central measuring section, shaped as a five-bar cage, is used for the measurement of the rolling moment.

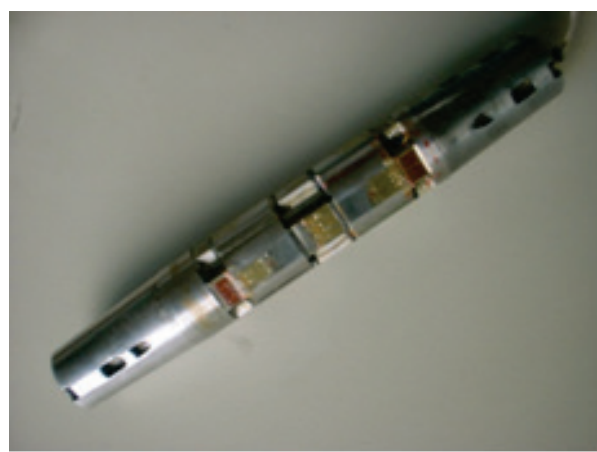

Figure 6 Five-component wind tunnel balance with semiconductor strain gauges

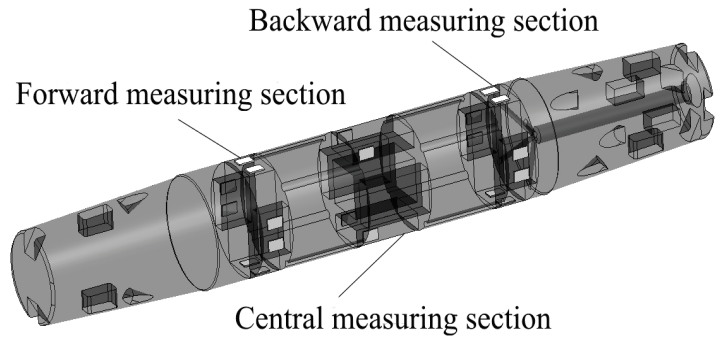

Figure 7 The balance measuring sections

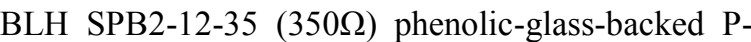
type silicon semiconductor strain gauges are used for all balance components connected in form of four-activearms bridges. The bridges excitation is provided by dedicated per-component constant-current power sources adjusted to deliver $18 \mathrm{~mA}$ current for each balance component. The positions of the balance measuring sections are shown in Fig. 7.

Table 2 Design loads of the five-component semiconductor strain gauge

\begin{tabular}{|c|c|c|c|c|}
\hline Component & $\begin{array}{c}\text { Design } \\
\text { load } \\
(\mathrm{N} / \mathrm{Nm})\end{array}$ & $\begin{array}{c}\text { Maximum } \\
\text { value of the } \\
\text { output signals } \\
(\mathrm{mV})\end{array}$ & $\begin{array}{c}\text { Maximum } \\
\text { errors } \\
(\% \mathrm{FS})\end{array}$ & $\begin{array}{c}\text { Standard } \\
\text { deviation of } \\
\text { the errors } \\
(\% \mathrm{FS})\end{array}$ \\
\hline$Y$ & 7000 & 480 & -0.102 & 0.034 \\
\hline$Z$ & 10100 & 540 & 0.162 & 0.040 \\
\hline$L$ & 300 & 400 & -0.156 & 0.054 \\
\hline$M$ & 660 & 700 & 0.076 & 0.028 \\
\hline$N$ & 340 & 500 & 0.144 & 0.048 \\
\hline
\end{tabular}

The accurate measurements of mechanical strain and deformations using semiconductor strain gauges necessarily demands to compensate the gauge output signals against undesirable temperature effects. For this balance, the compensation is accomplished by series of the resistor elements, whose resistance is independent on temperature. The resistances of the zero-balancing and shunt-compensation resistor elements as well as values of the electrical current for supplying the measuring bridge are determined in the balance calibration. The balance calibration is done using the composite loading method 
[18]. Tab. 2 lists the design loads of the five-component semiconductor strain gauge balance, maximum values of the output signals and gives a summary of achieved accuracy in the calibration. Tab. 1 and Tab. 2 show that the level of the signals obtained by the semiconductor measuring bridge is several times higher than the level of the signals obtained from foil measuring bridges. The high level of the signals is very important in the data reduction in the dynamic wind tunnel measurements.

\subsection{Procedure for Measurement of Static Aerodynamic Data}

During the T-38 wind tunnel dynamic measurements static aerodynamic data can also be measured. The accurate measurements of the static aerodynamic data in the dynamic wind tunnel tests lead to a shorter time of static aerodynamic measurements that always precede the wind tunnel dynamic measurements.

According to the T-38 wind tunnel dynamic test procedure, one control run, for each Mach number and model angle of attack, must be done before the dynamic wind tunnel run. In this particular run, cooled control wind tunnel run, the model is installed on the forced oscillation apparatus, but the apparatus is not forced to oscillate. During this run only static aerodynamic data is obtained. The control run is the static wind tunnel run. Such consecutive measurements provide the best conditions for the comparison of the measured static data in control wind tunnel run and dynamic wind tunnel run.

In the T-38 wind tunnel data acquisition system is based on Teledyne 64 channel "front end" system controlled by PC computer. The total sampling rate of the data acquisition system is $60 \mathrm{kHz}$. The data of all analog channels, in the test, are digitalized by 16-bit resolution A/D converter with overall accuracy of the acquisition system being about $0.05 \%$ to $0.1 \%$ full scale of the channel rate.

In the dynamic wind tunnel measurements, one wind tunnel run is done for each angle of attack of the model. The duration of each dynamic wind tunnel run was $12 \mathrm{~s}$, of which $8 \mathrm{~s}$ was the sampling data time. The channel of the oscillatory motion sensor and all channels of the balance are sampled with 1000 sample/s rate. In the wind tunnel static run (control run), all channels of the balance were sampled with $300 \mathrm{sample} / \mathrm{s}$ rate.

The components of the aerodynamic load in the body axis system are given in Fig. 8, where $X$ is aerodynamic axial force.

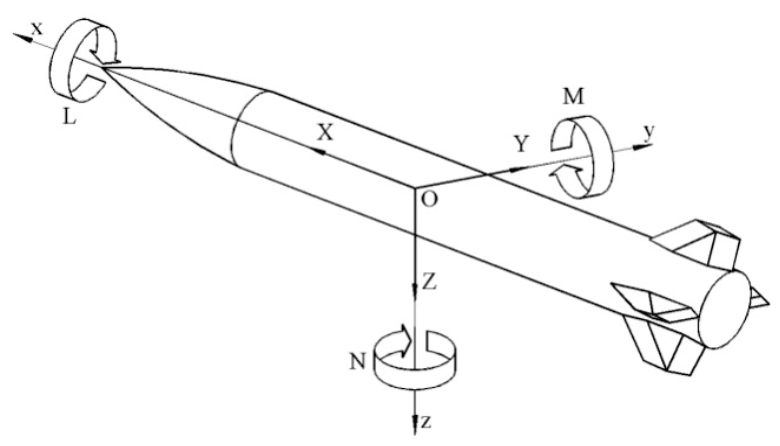

Figure 8 Body axis systems
The static aerodynamic coefficients in the body axis system are calculated from aerodynamic forces and moments which are measured by internal balance:

$$
\begin{aligned}
& C_{z}=\frac{Z}{q_{\infty} S} \\
& C_{m}=\frac{M}{q_{\infty} S d}
\end{aligned}
$$

where $C_{z}$ is normal force non-dimensional coefficient, $q_{\infty}$ is dynamic pressure, $C_{m}$ is pitching moment nondimensional coefficient, $S$ is a model reference area and $d$ is the model reference length.

\section{AERODYNAMIC SEMI-EMPIRICAL AND NUMERICAL PREDICTION}

The research of aerodynamic data, presented in the paper, consists of two groups of aerodynamic predictions: the semi-empirical aerodynamic predictions and numerical predictions with code of Computational Fluid Dynamics (CFD) incorporated into Ansys Fluent software [13]. The prediction research model of body was $0.1 \mathrm{~m}$ referent diameter and 10 referent diameter long the wind tunnel model.

The semi-empirical aerodynamic prediction $\left(\mathrm{ADP}_{1}\right)$ is done using aerodynamic prediction software RASAero [10]. The results of the aerodynamic prediction $\left(\mathrm{ADP}_{1}\right)$ are normal force aerodynamic coefficients and axial position of the centre of pressure of normal force, for range of Mach numbers and angle of attack to the value of 5 degrees. The values of pitch moment coefficient are derived from the results of normal force coefficient at resulted referential position on the model.

The second set of semi-empirical prediction $\left(\mathrm{ADP}_{2}\right)$ is done for normal force coefficient. This semi-empirical prediction is done with methods based on experimental and theoretical aerodynamic research of rockets and projectile and presented in $[11,12]$. The aerodynamic data, according to prediction $\mathrm{ADP}_{2}$, are derived for the same geometric parameters in the research as in the semiempirical aerodynamic prediction $\mathrm{ADP}_{1}$.

The aerodynamic numerical prediction simulations of the wind tunnel model are performed using the (CFD) code. The governing equation is based on Reynolds Averaged Navier Stokes equations (RANS), given by equations for the conservation of mass, momentum, energy and ideal gas law, presented in the following forms $[14,19,20]$ :

- continuity:

$\frac{\partial}{\partial x_{i}}\left(\overline{\rho u_{i}}\right)=0$

- momentum:

$$
\begin{aligned}
& \frac{\partial}{\partial x_{i}}\left(\overline{\rho u_{i} u_{j}}\right)= \\
& =-\frac{\partial \bar{p}}{\partial x_{i}}+\frac{\partial}{\partial x_{j}}\left[\mu\left(\frac{\partial \overline{u_{i}}}{\partial x_{j}}+\frac{\partial \overline{u_{j}}}{\partial x_{i}}-\frac{2}{3} \delta_{i j} \frac{\partial \overline{u_{i}}}{\partial x_{i}}\right)\right]+\frac{\partial}{\partial x_{i}}\left(-\overline{\rho u_{i}{ }^{\prime} u_{j}}{ }^{\prime}\right)
\end{aligned}
$$


- energy:

$$
\begin{aligned}
& \frac{\partial}{\partial t}\left(\rho h_{0}\right)+\frac{\partial}{\partial x_{j}}\left(\rho h_{0} u_{j}\right)= \\
& \frac{\partial p}{\partial t}+\frac{\partial}{\partial x_{j}}\left(u_{i}\left(\frac{\partial u_{i}}{\partial x_{j}}+\frac{\partial u_{j}}{\partial x_{i}}-\frac{2}{3} \delta_{i j} \frac{\partial u_{i}}{\partial x_{i}}\right)+\lambda \frac{\partial T}{\partial x_{j}}\right)
\end{aligned}
$$

- ideal gas:

$$
p=\rho R T
$$

where $p$ is mean pressure, $\rho$ is mean density, $\mu$ is molecular viscosity, $u_{i}$ are mean velocities, $h_{0}$ is total enthalpy, $\lambda$ is thermal conductivity. Reynolds stresses were given at term,

$$
-\overline{\rho u_{i}}{ }^{\prime} \overline{u_{j}}{ }^{\prime}=\mu_{t}\left(\frac{\partial \overline{u_{i}}}{\partial x_{j}}+\frac{\partial \overline{u_{j}}}{\partial x_{i}}\right)-\frac{2}{3}\left(\rho k+\mu t \frac{\partial \overline{u_{i}}}{\partial x_{i}}\right) \delta_{i j}
$$

where $\mu_{t}$ is turbulent or eddy viscosity, $k$ is turbulent kinetic energy. To correctly account for turbulence, Reynolds stresses are modeled in order to achieve closure of Eq. (4). The method of modelling employed utilizes the Boussinesq hypothesis to relate the Reynolds stresses to the mean velocity gradients within the flow.

The numerical researches are provided as two numerical results, presented in the paper as $\left(\mathrm{CFD}_{1}\right)$ and $\left(\mathrm{CFD}_{2}\right)$. The numerical simulation with two-equations turbulence model $k-\omega$, as shear stress transport SST variant was done mark $\left(\mathrm{CFD}_{1}\right)$, where the turbulent viscosity is computed through solution of two additional transport equations for the turbulent kinetic energy, and either the turbulence specific dissipation rate, $\omega,[14,17]$. The second model of the numerical simulation was fourequation transitional $S S T$ turbulence model (mark $\left.\mathrm{CFD}_{2}\right)$.

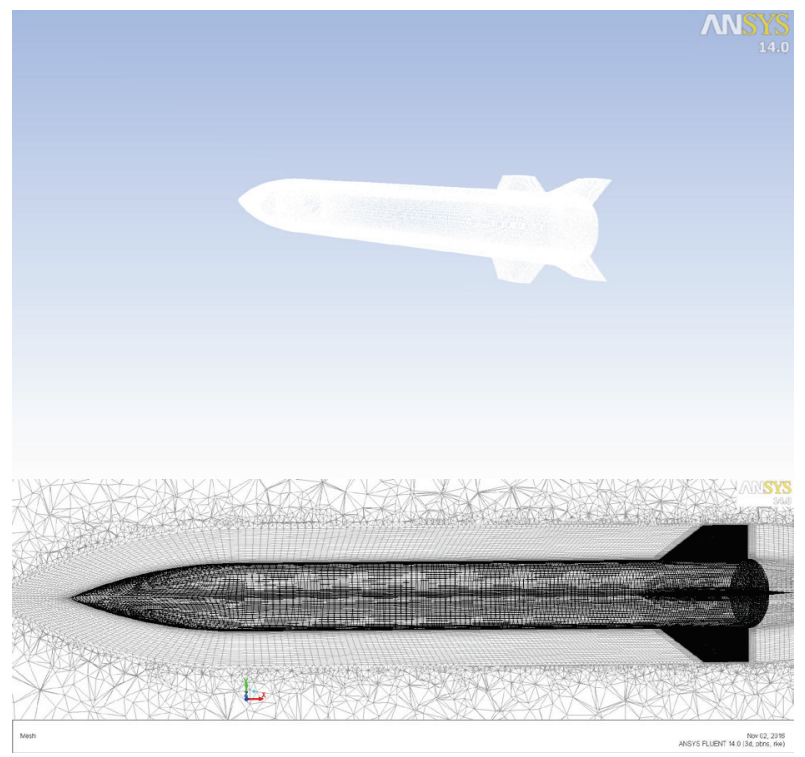

Figure 9 The mesh concept applied in the numerical simulation

The numerical discretization of the computational domain around the model was designed with hybrid mesh of tetrahedral and hexahedral cells. The computational domain of ellipsoid is created with longitudinal length of 80 referent diameter of model and lateral width of 40 referent diameter of model, Fig. 9. The spatial discretization schemes of the equations were second order upwind. The first computational domain consisted of 1.2 million of cells $\left(\mathrm{CFD}_{1}\right)$. The second mesh structure was modified, and consisted of 1.9 million of cells $\left(\mathrm{CFD}_{2}\right)$.

The outer boundaries were set to the free stream conditions at standard atmosphere for the total temperature $T=288 \mathrm{~K}$ and the total pressure $p=101325 \mathrm{~Pa}$. The inner boundary of the model was modelled as no-slip, isothermal wall boundary.

The criteria of convergence were constant values of aerodynamic coefficients of normal force and pitch moment, within last 100 iterations and the residuals below $5 \times 10^{-4}$, for $\left(\mathrm{CFD}_{1}\right)$ simulations and $5.4 \times 10^{-5}$ for $\left(\mathrm{CFD}_{2}\right)$ simulations.

Fig. 9 represents the mesh resolution near the wall of the model that is applied in the numerical simulations.

The numerical steady state simulations with twoequation turbulence model and 1.2 millions of cells mesh $\left(\mathrm{CFD}_{1}\right)$ were enabled to obtain the results with lower processor computing resources, and realized on eight cores processor for each Mach number and the angle of attack separately. The numerical simulations with fourequation model and 1.9 millions of cells mesh $\left(\mathrm{CFD}_{2}\right)$ are done for each Mach number and angle of attack on a higher processor computing resource, and significant extended processors time.

\section{EXPERIMENTAL, SEMI-EMPIRICAL AND NUMERICAL RESULTS}

The T-38 wind tunnel testing, the aerodynamic predictions and the numerical simulations are done for Modified Basic Finner model (MBFM) which is a wellknown standard model. This model is used for wind tunnel testing and verification of wind tunnels equipment as well as for the verification of different approaches for aerodynamic coefficients predictions. The MBFM model in the T-38 wind tunnel test section is shown in Fig. 10.

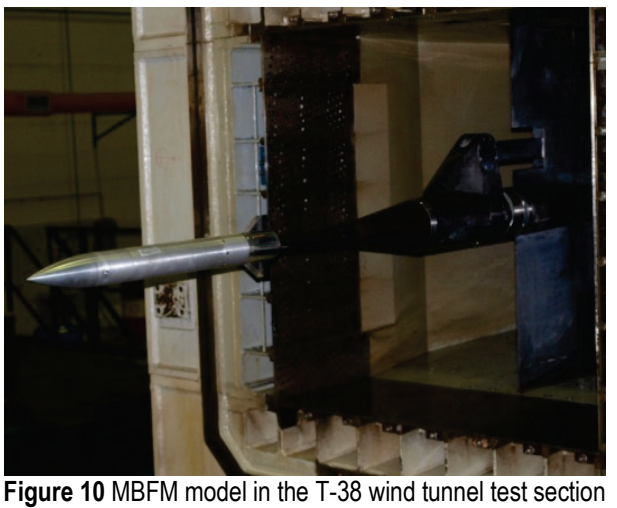

The wind tunnel tests were done at Mach numbers 0.6, 1.5 and 1.75. The static aerodynamic data were measured in the static and dynamic wind tunnel runs. The angle of attack of the model was in the interval from $-2^{\circ}$ to $5^{\circ}$ and roll angle was $0^{\circ}$. In the dynamic wind tunnel tests the model was forced to oscillate in pitch mode at 
amplitude $\pm 0.5^{\circ}$ and frequency of $10 \mathrm{~Hz}$. The signal of the balance measuring bridge for pitching moment in the static wind tunnel test for Mach number 1.75 and angle of attack $\alpha=0^{\circ}$ is shown in Fig. 11a). The signal of the pitching moment from the balance measuring bridge as well as the signal from the model primary oscillatory motion sensor (ODF) in the dynamic wind tunnel test for the same Mach number and angle of attack is shown in Fig. 11b).

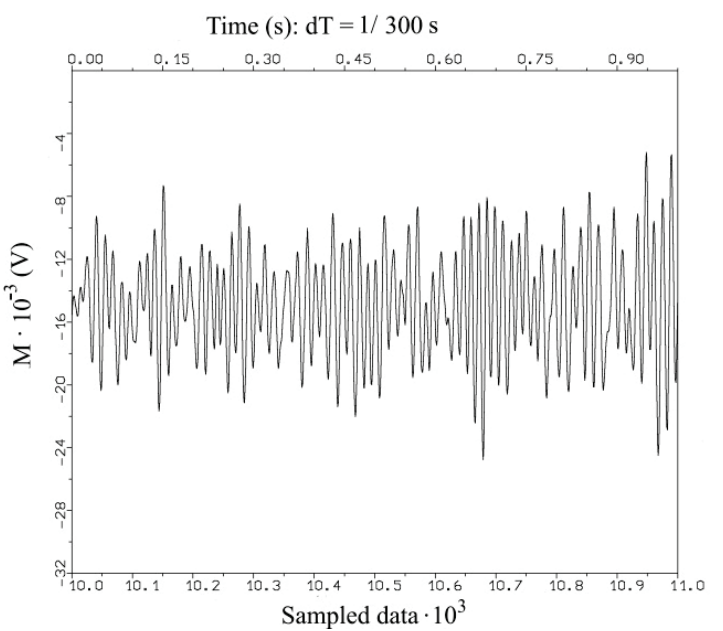

a)

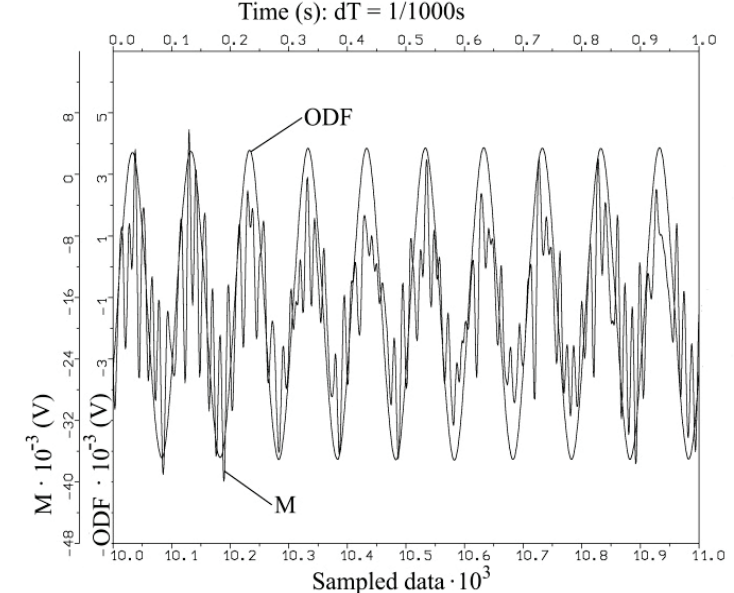

b)

Figure 11 Signal of the pitching moment in the static wind tunnel test a), signal of the pitching moment and model primary oscillatory motion sensor in the dynamic wind tunnel test b)

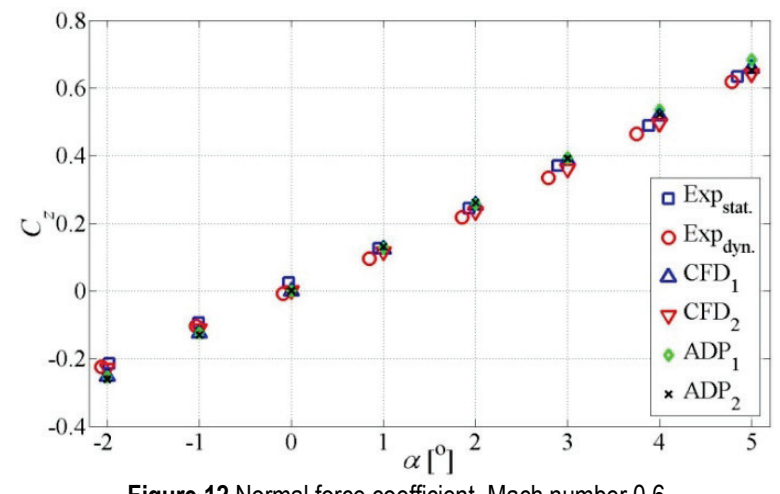

Figure 12 Normal force coefficient, Mach number 0.6

The aerodynamic predictions are done for three Mach numbers according to the experimental research, and the results derived for the range of angle of attack, $-2^{\circ}$ to $+5^{\circ}$.
Figures Fig. 12 to Fig. 17 show the results of the normal force coefficients and pitching moment coefficients obtained by static wind tunnel runs $\left(\operatorname{Exp}_{\text {stat }}\right)$, dynamic wind tunnel runs $\left(\operatorname{Exp}_{\mathrm{dyn}}\right)$, aerodynamic semiempirical predictions $\left(\mathrm{ADP}_{1}\right.$ and $\left.\mathrm{ADP}_{2}\right)$ and two sets of numerical simulations $\left(\mathrm{CFD}_{1}\right.$ and $\left.\mathrm{CFD}_{2}\right)$.

The presented values of normal force coefficient at subsonic Mach number, in Fig. 12, show very good agreements of all the different results at the range of the angle of attack. The experimental static and dynamic measurements results show close agreement. The close agreements of numerical results, between two methods, and also in the comparison to both experimental results are obviously very good. The semi-empirical predictions of both applied methods justified the recommendations of application in the initial research stage, as reliable preliminary results of static coefficients.

The results of the normal force coefficient at transonic Mach number, Fig. 13, show very close agreement of all applied methods.

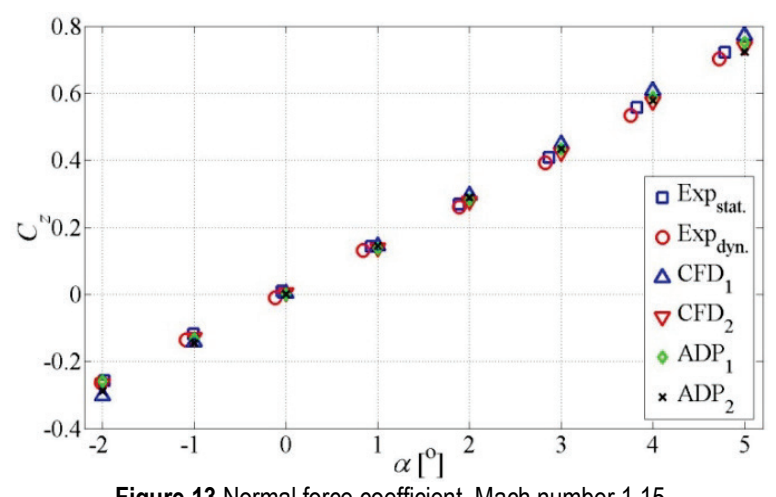

Figure 13 Normal force coefficient, Mach number 1.15

In Fig. 14 are presented the results of the normal force coefficient at supersonic Mach number, with almost insignificant differences of the experimental results, in relation to the numerical results. The semi-empirical results also show slightly greater values than other at higher values of angle of attack. The pattern of all experimental results is shown the accurate characteristics.

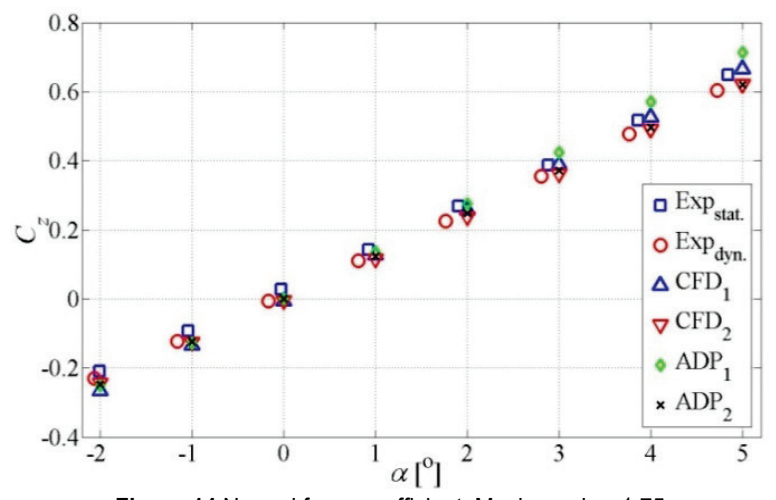

Figure 14 Normal force coefficient, Mach number 1.75

The pitching moment coefficients, presented in Fig. 15 , show close agreements of experimental results and numerical results. The small differences of the semiempirical results in relation to other results are insignificant, according to the initial prediction purpose.

Fig. 16 shows the pitching moment coefficient at transonic Mach number. The significant differences of the 
semi-empirical results in relation to other results are presented. The numerical results are mutually agreed and rather correlated to dynamic experimental results.

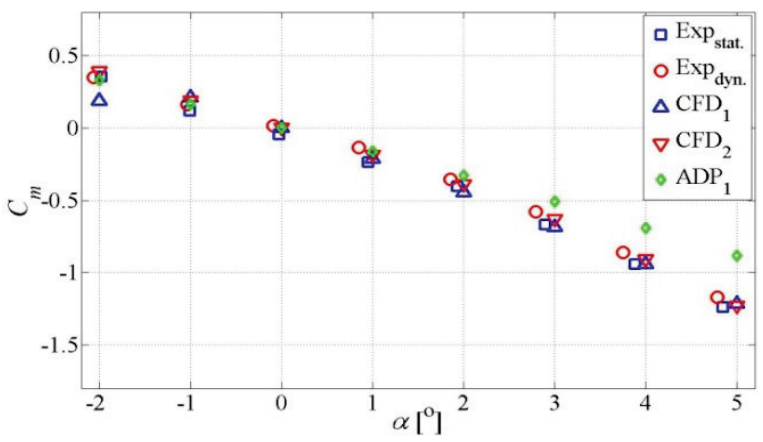

Figure 15 Pitch Moment coefficient, Mach number 0.6

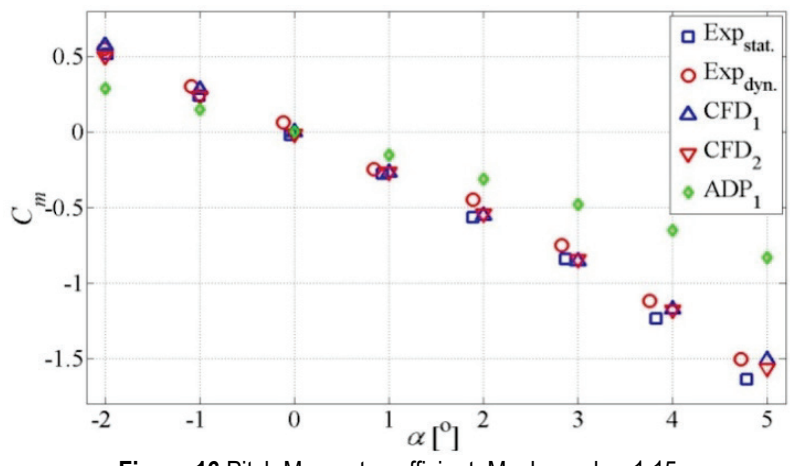

Figure 16 Pitch Moment coefficient, Mach number 1.15

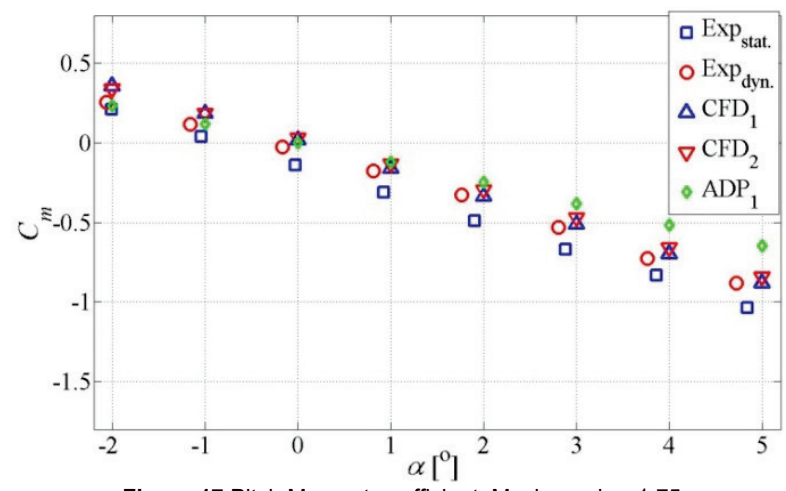

Figure 17 Pitch Moment coefficient, Mach number 1.75

The results of pitching moment coefficient, at supersonic Mach number are presented in Fig. 17 and demonstrate the good preliminary values and trend of semi-empirical results, with noticeable deviation with regard to experimental results. Close agreements are shown of numerical results and pertinent correlations to the dynamic experimental results. The presented set of results of experimental research and measurement methods justified the accuracy, the quality and the reliability of the applied tests, in correlation to conducted numerical research. The significance of the numerical research is to understand and support the conducted tests.

\section{CONCLUDING REMARKS}

The comparison of the results of normal force coefficients and pitching moment coefficients between the set of the wind tunnel data and the set of the predicted aerodynamic data for three Mach numbers is done. The semi-empirical aerodynamic predictions are based on standard geometric parameters of the standard projectile model, MBFM model, and it is expected to predict similar characteristic of aerodynamic coefficients of normal force and pitching moment. It is more important that the numerical (CFD) predictions of the aerodynamic data have shown very good agreements with experimental results. The represented experimental static and dynamic wind tunnel tests have shown close mutual agreement.

It is shown that the semiconductor strain gauge balance enables the accurate measurements of the static aerodynamic data in the static wind tunnel runs as well as in the dynamic wind tunnel runs. The optimal signal-tonoise ratios from the balance measuring bridges are reached using the semiconductor strain gauges. In deciding which experimental technique to use to obtain static aerodynamic data, primary consideration must be the purpose of the test. Generally, balance for static wind tunnel tests is relatively simple to use, allows rapid data reduction, and yields data of low uncertainty for moderate to large angles of attack. The dynamic testing is more complicated and data reduction is more involved and time consuming. However, the forced oscillation technique provides a method of accurate obtaining static data during dynamic wind tunnel tests.

\section{REFERENCES}

[1] Tropea, C., Yarin A., \& Foss J. F. (2007). Springer Handbook of Experimental and Fluid Mechanics: Force and Moment Measurement. Springer-Verlag Berlin Heidelberg. https://doi.org/10.1007/978-3-540-30299-5

[2] Samardžić, M., Anastasijević, Z., Marinkovski D., Ćurčić, D., \& Isaković, J. (2014). External six-component strain gauge balance for low speed wind tunnels. Scientific Technical Review, 64(3), 40-46.

[3] Almeida, A. B. R., Vaz, C. D., Urgueira, P. V. A., \& Borges, A. R. J. (2012). Using ring strain sensors to measure dynamic forces in wind-tunnel testing. Sensors and Actuators A: Physical, 185, 44-52. https://doi.org/10.1016/j.sna.2012.07.024

[4] AIAA. (2003). Recommended Practice: Calibration and Use of Internal Strain-Gauge Balances with Application to Wind Tunnel Testing. AIAA, AIAA-R-091-2003.

[5] Measurement of aerodynamic forces and moments in wind tunnels. Encyclopaedia of aerospace engineering / Z. Fan. In: R. Blockley, W. Shyy (Eds.), Online 2010: John Wiley \& Sons LTD, 2010. 766-778.

[6] Application Note 078. National Instruments. 2003. http//:bsesrv214.bse.vt.edu/Grisso/Ethiopia/Lectures/Instru mentation/DATAQ/AN078.pdf

[7] Younis, N. T.; Kang, B. (2011). Average effects of a strain gage. Journal of Mechanical Science and Technology, 25(1), 163-169. https://doi.org/10.1007/s12206-010-1020-1

[8] Hoffman, K. (1989). An introduction to measurements using strain gauges. Hottinger Baldwin messtechnik GmbH. Darm-stadt. Germany.

[9] Elfstrom, G. M. \& Medved, B. (1986). The Yugoslav $1.5 \mathrm{~m}$ trisonic blowdown wind tunnel. Proceeding of the $14^{\text {th }}$ AIAA Aerodynamic Testing Conference / West Palm Beach, AIAA Paper 86-0746-CP.

[10] RASAero - RASAero II, Rogers AeroscienceRASAero Aerodynamic and Flight Simulation Software, www.rasaero.com, 05.05.2015. and 19.09.2015.

[11] Jankovic S. (1978). Aerodynamics of projectiles (In Serbian), Faculty of Mechanical Engineering, Belgrade.

[12] Petrov K. P. (1977). Aerodynamics of rockets (In Russian), Masinostroenie, Moscow. 
[13] Ansys Inc., ANSYS FLUENT 14.0 and GAMBIT 2.1 licensed to VTI, 2010.

[14] Mulvany N. J., Chen, L., Tu, Y. J., \& Anderson, B. (2004). Steady-State Evaluation of Two-Equation RANS Turbulence Models for High-Reynolds Number Hydrodynamic Flow Simulations, DSTRO-TR-1564, DSTO Platform Sciences Laboratory, Victoria, Australia.

[15] Orlik-Rückeman, K. J. (1981). Review of techniques for determination of dynamic stability parameters. AGARDLS-114. The Advisory Group for Aerospace Research and Development, NATO Research and Technology Organisation. Brussles, Belgium.

[16] Ćurčić, D., Anastasijević, Z., Burzić, Z., Samardžić, M., Ilić, S., Isaković, J., \& Marinkovski, D. (2014). Analysis of the possibility of increasing sting stiffness in the T-38 wind tunnel. Technical Gazette, 21(6), 1371- 1375.

[17] Samardžić, M., Anastasijević, Z., Marinkovski, D., Isaković, J., \& Tančić, Lj. (2012). Measurement of pitch and roll-damping derivatives using semiconductor fivecomponent strain gauge balance. Proc. ImechEPartG: J. Aerospace Eng., 226(11), 1401-1411. https://doi.org/10.1177/0954410011424016

[18] Vuković, Đ., Samardžić, M., \& Marinkovski, D. (2012). Upgrade of the Balance Calibration System in VTI. Proceeding of $8^{\text {th }}$ Int. Symposium on Strain-Gauge Balance / $R U A G$, Lucerne, Switzerland, 1-9.

[19] Sahu, J. (2011). Virtual fly-out simulations of a spinning projectile from subsonic to supersonic speeds. The $29^{\text {th }}$ AIAA Applied Aerodynamics Conference / Honolulu, AIAA 2011-3026. https://doi.org/10.2514/6.2011-3026

[20] Jerković, D. \& Regodić, D. (2011). The influence of the aerodynamic coefficients on the trajectory parameters of the classic projectile, Military Technical Courier. Scientific Magazine of MoDR. Serbia, Year LIX, April - June, 2(2011), 5-28.

\section{Contact information:}

Habib BELAIDOUNI, graduate student

$\mathrm{PhD}$ applicant at Military Academy,

University of Defence,

Pavla Jurisica Sturma, No. 33, 11000, Belgrade, Serbia

E-mail: h_belaidouni@yahoo.fr

Marija $\bigoplus$. SAMARDžIĆ, leading researcher

Military Technical Institute

Ratka Resanovića, No. 1, 11000, Belgrade, Serbia

E-mail: majasam@ptt.rs

Damir D. JERKOVIĆ, leading researcher

University of Defence

Military Academy

Pavla Jurisica Sturma, No. 33, 11000, Belgrade, Serbia

E-mail: damir.jerkovic@va.mod.gov.rs

Saša ŽIVKOVIĆ, leading researcher

Military Technical Institute

Ratka Resanovića, №. 1, 11000, Belgrade, Serbia

E-mail: sasavite@yahoo.com

Zoran RAJIĆ, leading researcher

Military Technical Institute

Ratka Resanovića, No. 1, 11000, Belgrade, Serbia

E-mail: zoran.rajic@vti.vs.rs

Dušan ĆURČIĆ, leading researcher

Military Technical Institute

Ratka Resanovića, №. 1,11000, Belgrade, Serbia

E-mail: dusan.curcic@vti.vs.rs

Aleksandar KARI, Assistant Professor

University of Defence

Military Academy

Pavla Jurisica Sturma, No. 33, 11000, Belgrade, Serbia

E-mail: aleksandarkari@gmail.com 